\title{
RAÍZES E INTENÇÃO DA TRADUÇÃO OFICIAL DA BÍBLIA DA CNBB
}

The Roots and Intentions of the Official Bible Translation of the Brazilian Bishops Conference

\author{
Johan Konings * \\ Luís Henrique Eloy e Silva **
}

RESUMO: Este artigo pretende explicar a intenção que presidiu à produção da "tradução oficial" da Bíblia pela Conferência Nacional dos Bispos do Brasil (CNBB), bem como o pano de fundo histórico desde as origens da Bíblia como conjunto literário. Na Introdução é mostrado que o Concílio Vaticano II exprimiu o desejo de uma nova tradução latina oficial e de traduções vernáculas nela baseadas. A primeira parte do artigo evoca brevemente o uso de traduções bíblicas desde a constituição da Bíblia no judaísmo e no cristianismo primitivo até a Vulgata de Jerônimo, nos albores do século V. A segunda parte mostra o caminho da Vulgata no cristianismo latino, com ênfase no seu reconhecimento no Concílio de Trento, até a publicação da Nova Vulgata depois do Concílio Vaticano II. Nesta parte mostram-se exemplos das modificações introduzidas em relação à antiga Vulgata em consideração do progresso da crítica textual e da exegese bíblica. A terceira parte explica a elaboração, sob os auspícios da $\mathrm{CNBB}$, de uma versão brasileira baseada nos textos bíblicos em língua original, segundo os critérios da Nova Vulgata, principalmente para a liturgia, a catequese e os documentos oficiais.

PALAVRAS-CHAVE: Bíblia. Tradução. Nova Vulgata.

ABSTRACT: This article aims to explain the motivations that inspired the production of the "official translation" of the Bible by the National Conference of Bishops of Brazil (CNBB), as well as investigating the historical background of

* Faculdade Jesuíta de Filosofia e Teologia, Belo Horizonte, Minas Gerais, Brasil.

** Pontifícia Universidade Católica de Minas Gerais, Belo Horizonte, Minas Gerais, Brasil 
the origins of the Bible as a literary set. The Introduction shows that the Second Vatican Council expressed a desire for a new, official, Latin translation and other vernacular translations based on it. The first part of the article briefly explores the use of biblical translations, from the compilation of the Bible in Judaism and early Christianity to the Vulgate of Jerome in the early 5th century. The second part of this work shows the path of development for the Vulgate in Latin Christianity, with emphasis on its recognition at the Council of Trent until the publication of the New Vulgate after the Second Vatican Council. Included are examples of modifications introduced in relation to the old Vulgate considering the progress of textual criticism and exegetical interpretation. The third part concerns the composition, under the auspices of the CNBB, of a Brazilian version based on the biblical texts in their original languages according to the criteria of the New Vulgate and especially for use in the liturgy, catechesis and official documents.

KEYWORDS: Bible. Translation. Nova Vulgata.

\section{Introdução}

С m 25 de abril de 1979, festa de São Marcos evangelista, o Papa João $\amalg$ Paulo II apresentou solenemente a nova tradução bíblica que doravante serviria de referência para a Igreja Católica de rito latino, a chamada Nova Vulgata ou Neovulgata. Resumimos as palavras da Constituição apostólica Scripturarum Thesaurus, promulgada nessa ocasião. ${ }^{1}$

O Concílio recomendou dar continuidade à revisão da Vulgata, já efetuada quanto aos Salmos, para oferecer uma nova tradução latina (DV, n. 22; SC, n. 91). Para este fim Paulo VI constituiu uma Comissão Pontifícia especial. Na revisão

teve-se em conta palavra por palavra o texto antigo da edição latina da Vulgata, quando os textos primitivos são referidos exatamente, tais como os apresentam as atuais edições críticas; mas esse texto foi prudentemente corrigido quando deles se afasta ou os refere com menor exatidão. Para isso, foi usado o latim cristão bíblico, de maneira que a devida estima da tradição se conjugasse com as justas exigências da ciência crítica (Aloc. de Paulo VI, 23 de Dezembro de 1966; A.A.S., LIX, 1967, p. 53 s.).

Assim nasceu a Nova Vulgata (NVg), publicada em volumes separadas a partir de 1969, reunidos na Editio typica prior de 1979 e na Editio typica altera de 1986 (ambas na Libreria Editrice Vaticana). Ela tem sólida base científica, capaz de sustentar estudos bíblicos sérios também onde não se dispõe de Faculdades e Institutos de alto padrão. Sobretudo, a Scripturarum

\footnotetext{
${ }^{1}$ JOÃO PAULO II, Papa. Disponível em: <http://w2.vatican.va/content/john-paul-ii/pt/ apost_constitutions/documents/hf_jp-ii_apc_19790425_scripturarum-thesaurus.html>. Acesso em: 26 out. 2019.
} 
thesaurus deseja que a Nova Vulgata sirva "como base para traduções em língua moderna que se destinem ao uso litúrgico e pastoral". A CNBB deu ouvido a este apelo e, depois de publicar em 2002 uma tradução provisória, viu coroado o esforço de vinte e cinco anos pela publicação da "Tradução oficial da CNBB da Bíblia sagrada" em 2018. É a essa publicação que se dedica o presente estudo.

\section{Do nascimento da Bíblia até a Vulgata de Jerônimo}

$\mathrm{O}$ assunto de que trataremos neste artigo diz respeito a uma tradução "oficial" da Bíblia, destinada especialmente à liturgia e à pastoral. Este último termo é, às vezes, entendido exclusivamente no sentido pedagógico, de explicação ou até tradução simplificante. Sem negar o valor de tais esforços pedagógicos, é bom lembrar que, neste caso, se trata de uma tradução oficial, de referência, e nisso, exatamente, consiste seu valor pastoral específico. A "oficialidade" é também uma função pastoral.

Algo que os estudiosos da Bíblia facilmente esquecem é que a Bíblia serviu originalmente, e continua servindo até hoje, para a liturgia. É com vistas à liturgia que a Bíblia recebeu sua forma de livro, composto de diversos escritos surgidos da tradição narrativa e celebrativa da comunidade. Sem a preocupação em reunir, para o louvor no Templo e a leitura na sinagoga, os textos dispersos da tradição de Israel, não teríamos o Tanak, ${ }^{2}$ e o mesmo se deve dizer das escrituras cristãs do Novo Testamento.

Desde o início, o texto da "Bíblia", quer na forma judaica (o Tanak), quer na forma alexandrina (a Septuaginta), quer na forma bizantina (o textus receptus ${ }^{3}$ ), quer na forma latina (a Vetus Latina e a Vulgata), tanto no original como em tradução, deve se situar entre a linguagem formal e a popular, a primeira tendendo a imobilizar-se, a outra, a mudar continuamente em função do uso cotidiano. O Tanak foi constituído como conjunto no momento em que o hebraico já não era linguagem do povo, mas sim do Templo e da sinagoga, a ponto de necessitar de paráfrase (targum). A Septuaginta, escrita principalmente em grego koiné (isto é, comum) de cunho alexandrino, quando foi adotada pelo cristianismo do Mediterrâneo oriental já não apresentava mais o grego que o povo falava pela rua. $\mathrm{O}$ mesmo deve ter acontecido com a Vulgata de Jerônimo (Vg), que usa um

\footnotetext{
${ }^{2}$ A Bíblia hebraica: Lei, Profetas e Escritos (Torah, Neviim, Ketuvim).

${ }^{3}$ Textus receptus, denominação um tanto imprecisa para a LXX e o NT adotados nas Igrejas Orientais de língua grega, porém não com estrita uniformidade. O termo tornou-se referência, na Renascença e primeira Modernidade, para as traduções baseadas nos originais hebraicos e gregos, mas as descobertas ulteriores de milhares de manuscritos tornam, hoje, o textus receptus superado como referência científica.
} 
latim mais ou menos culto, enquanto nas periferias do Império o baixo latim ia gerando as futuras línguas neolatinas.

Isso tem relação com a estrutura do culto da escuta da Palavra, que tem sua origem na sinagoga judaica. Para representar a tradição, o texto exige relativa estabilidade, mas para poder ser entendido, exige o targum, a paráfrase que, porém, nunca poderá suplantar o texto, a tal ponto que, inicialmente, era proibido colocar o targum por escrito.

Uma liturgia baseada na forma escrita da tradição religiosa - o livro sagrado - precisará sempre de um texto fixado (seja na língua original, seja em tradução de algum modo autorizada) ao lado da paráfrase que o explique. A tradução "formal" (não verbalista) serve para a preleção e o uso oficial, enquanto as traduções mais dinâmicas, ou mesmo abertamente perifrásticas (as paráfrases), dependendo de destinatários e intenção, respeitarão, em grau maior ou menor, a semelhança verbal com o original que lhes confere plausibilidade (pois, mesmo na paráfrase, o original deve ser reconhecível). Assim, na Igreja cristã ocidental do início da Idade Média, onde a Vulgata de Jerônimo servia para a preleção litúrgica, encontramos traduções ora resumidas, ora ampliadas, em vernáculo, como, por exemplo, as traduções góticas, românicas etc. ${ }^{4}$ Ao mesmo tempo, a Vulgata divulgou-se apenas paulatinamente, muitas vezes hibridizada por vestígios da Vetus Latina. ${ }^{5}$

É nesta tensão entre a conservação do texto primitivo e a necessidade de uma tradução interpretativa, compreensível para novas gerações de ouvintes/leitores, que devemos entender a história da tradução chamada de Vulgata.

Os primeiros cristãos, de modo geral, constituíram sua "escritura" na base da corrente tradução grega do Antigo Testamento (AT), a Septuaginta (LXX). Olhando para os autores do Novo Testamento (NT), esta presença constante da LXX se constata tanto em Paulo, Marcos e Lucas, voltados para o Ocidente, como em Mateus e João, cujo olhar vai, antes, para o Oriente. O Antigo Testamento dos primeiros cristãos era a Bíblia judaica em língua grega, a Septuaginta. Por isso, percebe-se no uso da Bíblia pelos primeiros cristãos a presença de livros que não constam da Bíblia hebraica, mas sim da LXX (os deuterocanônicos, também chamados, de modo menos preciso, de apócrifos).

Enquanto as Igrejas cristãs orientais se servem, até hoje, da Septuaginta para o Antigo Testamento e dos textos gregos originais para o Novo, o mundo

\footnotetext{
${ }^{4} \mathrm{Na}$ Idade Média, e ainda muito depois, a Bíblia era divulgada entre o povo por meio de resumos principalmente narrativos, a "Bíblia historial", ou "História sagrada".

${ }^{5}$ Usamos este termo para nos referir às traduções latinas antes da Vulgata. As distinções entre Afra, Ítala e Hispânica não são muito operacionais segundo o atual estado das pesquisas.
} 
ocidental precisou de traduções em vernáculo latino, que surgiram bem cedo tanto na "África romana" como no continente europeu (SCHÄFER, 1958; REICHMANN, 1980, p. 178-182).

Desde cedo, a Igreja teve de enfrentar a multiplicação de traduções. Isso levou o grande Orígenes, no Egito e no Oriente mediterrâneo, já no século III, a compor obras de comparação entre as diversas traduções em voga. A mais conhecida é a Hexapla, que compara, em seis colunas paralelas, as traduções do Antigo Testamento. Infelizmente, não sobreviveu à invasão dos muçulmanos. Um século depois, Jerônimo deparou com o mesmo problema no mundo ocidental, sobretudo na África do Norte. ${ }^{6}$ A variedade e a diminuída confiabilidade das traduções fizeram com que o papa Dâmaso I (366-384) confiasse a Jerônimo a tarefa de promover uma tradução latina autorizada, tarefa que ele, em boa parte, cumpriu, embora sem concluir a obra. ${ }^{7}$ Este fato, e a expansão vertiginosa do cristianismo nesses tempos de grande divisão política e difícil comunicação, dificultou a adoção unânime da tradução de Jerônimo no mundo latino. Quando o Concílio de Trento, em 1546, reagindo ao surgimento de traduções não controladas no seio da Reforma protestante, declarou "autêntica" a "vetus et vulgata editio" (DH, n. 1506-1508) atribuída a Jerônimo, o texto ainda não estava cientificamente estabelecido. Aliás, até hoje os monges do mosteiro beneditino de San Girolamo em Roma estão empenhados na constituição de uma exaustiva edição crítica da Vulgata.

\section{Da Vulgata à Nova Vulgata}

A obra atribuída a Jerônimo não era perfeita. Realizada, em parte, por colaboradores ou continuadores, mostrava pouca firmeza gramatical e demasiada variação no vocabulário. Encontrou críticas desde o início da Era Moderna. O Papa Pio XII mandou traduzir novamente os Salmos (1945). Finalmente, como acima apontado, o Concílio Vaticano II pediu uma nova tradução completa, a "Nova Vulgata", que retoma a Vulgata de Jerônimo segundo a edição de estudo de $1969,{ }^{8}$ para torná-la mais adequada aos modernos textos críticos da Bíblia Hebraica, ${ }^{9}$ da Septuaginta ${ }^{10}$

\footnotetext{
${ }^{6}$ Os manuscritos latino-europeus ainda conservados parecem mais novos e mais influenciados pelo grego, que na África não era tão divulgado (SCHÄFER, 1958).

${ }^{7}$ A Vulgata foi completada depois da morte de Jerônimo. Em alguns livros ele nem chegou a colocar a mão. Cf. Praenotanda. In: Nova Vulgata bibliorum sacrorum editio [...]. Ed. tipica altera. Città del Vaticano: Libreria Ed. Vaticana, 1996. p. 13-25.

${ }^{8}$ BIBLIA Sacra Vulgata. Stuttgart: Württembergische Bibelanstalt, 1969. 2 v.

${ }^{9}$ ELLIGER, K.; RUDOLPH, W. (Ed.). Biblia hebraica stuttgartensia. Stuttgart: Deutsche Bibelgesellschaft, 1967/77.

${ }^{10}$ RAHLFS, Alfred (ed.). Septuaginta: id est Vetus Testamentum graece iuxta LXX interpretes. 9.ed. Stuttgart: Deutsche Bibelstiftung, 1935. 2 v.
} 
e do NT grego. ${ }^{11}$ Repetiu-se, no fundo, o intento de Jerônimo de oferecer uma tradução latina confiável, servindo de padrão referencial para toda a Igreja Católica de rito latino. Portanto, não se trata de uma edição crítica da Vulgata de Jerônimo. A Nova Vulgata é uma obra nova, uma nova tradução dos originais hebraicos, aramaicos e gregos criticamente verificados, análoga à obra de Jerônimo ${ }^{12}$ e cuidadosamente cotejada com ela.

Devemos compreender bem a intenção desse empreendimento, que, segundo a Constituição Apostólica Scripturarum Thesaurus cumpre um desejo do Concílio Vaticano II e do Papa Paulo VI. Além de se referir à Constituição Sacrosanctum Concilium n. 91, que solicita a conclusão da nova tradução latina dos Salmos para o ofício litúrgico, João Paulo II se refere também à Constituição Dei Verbum, n. 22, que reza:

É preciso que o acesso à Sagrada Escritura seja amplamente aberto aos fiéis. Por isso, desde o início a Igreja acolheu como sua a conhecida antiquíssima versão do Antigo Testamento, chamada dos Setenta; e tem sempre em honrosa consideração as outras versões orientais e as versões latinas, principalmente a chamada Vulgata. Porém, como a palavra de Deus deve estar à disposição de todas as épocas, procura a Igreja com materna solicitude que se façam versões adequadas e corretas para as diversas línguas, sobretudo a partir dos textos originais dos Livros Sagrados. Se, segundo a oportunidade e com a aprovação da autoridade da Igreja, essas traduções se fizerem em colaboração com os irmãos separados, poderão ser usadas por todos os cristãos.

Será que esse desejo não aponta antes para traduções ecumênicas, como, por exemplo, a TOB francesa ${ }^{13}$ e a Einheitsübersetzung alemã, ${ }^{14}$ do que para uma nova tradução em latim? A resposta a esta pergunta está no caráter eclesiástico-institucional e pastoral dessa tradução: necessitou-se de uma tradução que fosse referência para toda a Igreja Católica de rito latino; e, apesar de seus defeitos, a Vulgata de Jerônimo oferecia um excelente ponto de partida para isso.

\footnotetext{
${ }^{11}$ ALAND, Kurt et alii. The Greek New Testament. United Bible Societies (U.S.A.), o texto grego é idêntico ao de NESTLE-ALAND, Novum Testamentum graece. 26.ed. Stuttgart: Deutsche Bibelgesellschaft, 1979.

12 A Constituição Scripturarum Thesaurus não diz que a Vulgata de Jerônimo seja a "base", mas que se deve revisar (recognoscere) palavra por palavra a Vulgata, portanto, em todo o seu conteúdo, que foi declarado canônico pelo Concílio de Trento. A "base" científica da nova tradução são os documentos antigos julgados mais autênticos, sujeitos à reavaliação segundo a ciência da crítica textual. O texto canônico, que servirá de regra (orientação) da fé, deverá, por razões pastorais, tomar decisões autorizadas mesmo na incerteza científica. Por razões semelhantes poderá conservar lições que, cientificamente, são julgadas menos originais, mas que são úteis para a fé (p.ex., a perícope da adúltera e o final "canônico" do evangelho de Mc).

${ }^{13}$ LA BIBLE: Traduction oecuménique. Paris: Cerf, 1975-1976. 2 v.

${ }^{14}$ De fato uma edição católica, com colaboração de biblistas protestantes, publicada a partir de 1980.
} 
Durante dois milênios criou-se, na Igreja ocidental, uma tradição linguística muito devedora às antigas traduções latinas e, sobretudo, à antiga Vulgata, a qual, sem a mínima dúvida, supera todas as outras traduções latinas, tanto no aspecto linguístico como no aspecto da fidelidade aos originais. Colaborou para o desenvolvimento do latim acadêmico nas universidades medievais e modernas e influenciou também as traduções vernáculas que se multiplicaram antes e depois da Reforma protestante. A tradução alemã feita por Lutero, por exemplo, deve muito à Vulgata. A Vulgata é um monumento religioso e cultural nos países da cristandade latina tradicional, mesmo depois da Reforma protestante. Na Igreja católica ocidental a língua latina é até hoje a "língua franca". Os textos do Concilio Vaticano II, os documentos pontifícios e outros são publicados em latim como texto autêntico ou referencial. Por outro lado, o atual conhecimento material dos antigos manuscritos e o aprofundamento linguístico-semântico puseram à luz as muitas imperfeições da Vulgata. Jerônimo não dispunha de um acervo computorizado com milhares de manuscritos bíblicos, nem de um exército de colaboradores, como hoje têm os diversos institutos de crítica textual da Bíblia. Exatamente por razões ecumênicas e de cultura universal, tornou-se necessário atualizar o projeto de Jerônimo. E essa atualização se estende às traduções "eclesiásticas" (oficiais) nas diversas partes da Igreja de rito latino, como foi o caso da tradução oficial da Bíblia preparada, pela CNBB, no Brasil.

Distinguem-se, assim, diversas tarefas, todas elas legítimas e urgentes. Em primeiro lugar, providenciar um texto cientificamente aproximado aos manuscritos mais antigos e confiáveis dos textos hebraicos e gregos. ${ }^{15}$ Em segundo lugar, estabelecer um texto oficial ou de referência para a Igreja Católica de rito latino: é este o intento da Nova Vulgata, sempre procurando manter o que na antiga Vulgata é válido e levando em consideração a tradição religiosa e cultural que ela ajudou a criar e manter. Terceiro, completar a edição crítica do texto da antiga Vulgata na sua forma original do IV-V século d.C. ${ }^{16}$ Todavia, como aperfeiçoar a Vulgata se sua forma original não está totalmente estabelecida? Não é um obstáculo. A Nova Vulgata é uma tradução nova. De modo pragmático e com fins pastorais, utiliza como modelo a antiga Vulgata ${ }^{17}$ e, como meio de verificação científica, as recentes edições de estudo dos antigos manuscritos bíblicos.

Alguém poderá perguntar onde ficou, então, a "verdade bíblica". A inerrância bíblica não se refere às letras, mas ao sentido que a Escritura mediante a interpretação na comunidade de fé propõe para a nossa salvação (DV,

\footnotetext{
${ }^{15}$ É nesta perspectiva que foram produzidas a TOB francesa e a Einheitsübersetzung alemã.

${ }^{16}$ Tarefa imensa que, desde a primeira parte do século XX, está sendo levada adiante, principalmente, pelos monges do mosteiro de San Girolamo em Roma.

${ }^{17}$ Sobretudo no texto sixto-clementino subsequente ao Concílio de Trento e na recente edição de estudo de 1969 (BÍBLIA Sacra, 1969).
} 
n. 11). Um erro ou uma palavra omitida em alguma forma do texto não põe em perigo, como às vezes ainda se pensa, a salvação. A fé se alimenta da Palavra de Deus em sua totalidade, ultrapassando a letra da Bíblia. O apego à letra não salva ninguém $(2$ Cor 3,6$)$. O reconhecimento de uma tradução bíblica pelo Magistério refere-se à sua autenticidade jurídica, não à autenticidade crítica. ${ }^{18} \mathrm{O}$ texto da Bíblia é um instrumento, um dos veículos dos quais a onitranscendente autocomunicação de Deus se serve para nos envolver em seu divino diálogo de amor. Não devemos colocar o texto da Bíblia no lugar de Deus: seria idolatria.

Por que, então, tanto cuidado, tanto investimento? Porque o serviço da fé merece ser atendido com o maior empenho. Será que esta mais nobre comunicação não merece esse cuidado, muito mais que as redes de tv e coisas semelhantes? A Bíblia não é Deus, mas nos coloca diante do $\mathrm{Nu}-$ minoso, inspirando e conduzindo experiências individuais e comunitárias do Santo, as quais são "inerrantes" no efeito de nos conduzir ao Sentido Supremo de nossa vida.

E em que resulta o aperfeiçoamento pretendido pela NVg? Em primeiro lugar, o latim melhorou muitíssimo. Em segundo lugar, realizou-se um bom trabalho de crítica textual, não somente quanto às formas da antiga Vulgata, mas à transmissão manuscrita da Bíblia inteira, não só nos idiomas originais, mas, eventualmente, em traduções mais primitivas que os antigos documentos conservados em idioma original, como as lições da Septuaginta que são anteriores ao "Texto Massorético" (TM) hebraico, fixado somente no início da Idade Média pelos massoretas.

Posto isso, podemos mostrar alguns exemplos desse "aperfeiçoamento" em nome da crítica textual propriamente, ou seja, da restauração do texto bíblico segundo os documentos mais confiáveis.

Quanto ao AT, citemos apenas alguns exemplos de correções aplicadas à antiga Vulgata pela NVg:

${ }^{18}$ Cf. Pio XII, na Divino Afflante Spiritu (1943), n. 14: “ Nem vá alguém pensar que o sobredito uso dos textos originais, feito segundo as regras da crítica, é contrário a quanto o concílio de Trento sabiamente decretou a respeito da Vulgata latina. [...] Quanto à Vulgata, se o concílio Tridentino ordenou que ela fosse a tradução latina que todos usassem como autêntica, primeiro, este decreto, como todos sabem, é só para a Igreja latina, e para o uso público da Escritura; depois, em nada diminui a autoridade e valor dos textos originais.[...] Portanto esta autoridade preeminente ou autenticidade da Vulgata decretou-a o concílio não principalmente por motivos de crítica, mas antes pelo uso legítimo que dela se fez na Igreja durante tantos séculos; uso que prova estar ela, no sentido em que a entendeu e entende a Igreja, completamente isenta de erros no que toca à fé e aos costumes; de modo que, como a mesma Igreja atesta e confirma, se pode nas disputas, preleções e pregação alegar seguramente e sem perigo de errar; por isso esta autenticidade propriamente não se chama 'crítica' mas 'jurídica'." Disponível em: <http://w2.vatican.va/content/pius-xii/pt/encyclicals/ documents/hf_p-xii_enc_30091943_divino-afflante-spiritu.html>. Acesso em: 29 out. 2019. 
Gn 31,53: Vg e TM esclareceram a expressão “o Deus de Abraão e o Deus de Nacor" pela inserção "o Deus de seus pais"; a NVg e o grego não têm essa inserção.

Gn 36,2.14: com base na LXX, o siríaco e o grego, a NVg corrige o TM e a Vg fazendo de Aná o filho e não a filha de Sebeon.

1Sm 8,16, NVg e grego: "[O rei] tomará vossos escravos e escravas e vossos melhores bois e jumentos" (Vg e TM: [...] vossos escravos e escravas $e$ vossos melhores jovens e jumentos").

Alguns aperfeiçoamentos foram aplicados em nome da estilística, da estética, da exatidão gramatical ou da clareza. Neste sentido, as glosas explicativas características da antiga Vg não apenas foram conservadas, mas até ampliadas, como se nota no exemplo abaixo:

Gn 16,14: a Vg substituiu o nome do poço beer lachai roi (TM) pela tradução “o poço do que vive e me vê" (a LXX interpreta de outro modo). A NVg mantém o nome em hebraico e acrescenta a tradução em parêntese: "laharoi (isto é do que vive e me vê)", justificando na nota de rodapé: "perspicuitatis causa".

Correções maiores encontramos no Saltério. Os Praenotanda explicam que se conservou o Saltério Galicano usado nas edições modernas da $\mathrm{Vg}$, quando representa de modo adequado o texto massorético. Onde, porém, o TM parece insustentável, recorre-se à LXX. Onde nem assim se consegue um texto minimamente claro e condizente com o conjunto da oração, recorre-se à correção hipotética (conjetura) que menos modifique o texto consonântico hebraico. ${ }^{19}$ Do ponto de vista científico seria melhor deixar o texto na forma defeituosa que se conseguir estabelecer, ${ }^{20}$ mas a $\mathrm{NVg}$ é uma bíblia pastoral!

Quanto aos livros Tobias e Judite, que Jerônimo segundo seu próprio dizer traduziu em um dia, fez-se um trabalho de reconstituição crítica a partir das principais versões da LXX e de alguns valiosos códices da Vetus Latina (Vercellensis e Bernensis). De modo semelhante foram tratados os livros dos Macabeus, que Jerônimo nunca traduziu.

Modificações maiores ocorreram no Sirácida (Eclesiástico). Conservando a prioridade do texto latino (já que nem as versões gregas nem os fragmentos hebraicos podem reclamar maior originalidade) enriqueceu-se o texto da $\mathrm{Vg}$ com significativas emendas sugeridas pelo trabalho comparativo. O resultado é que o texto ficou ainda mais longo que o já longo "texto grego II" $^{21}$ e o de Jerônimo, apesar do cuidado de evitar repetições.

A NVg não foge dos semitismos, quando suficientemente conhecidos na tradição do latim eclesiástico, como por exemplo cornu salutis ("chifre da

${ }^{19}$ A vocalização do hebraico foi introduzida no TM no início da Idade Média.

${ }^{20}$ Como faz, em determinados casos, a TOB (LA BIBLE, 1975-1976).

${ }^{21}$ A respeito disso, NVg, 1998, p. 18 (Praenotanda). 
salvação"). Isso é um aviso para nós: também no português popular tradicional ocorrem semitismos bíblicos ou elementos análogos, que são melhor conhecidos que as pretensas equivalências do português coloquial de hoje.

Quanto ao NT, os Praenotanda observam que os revisores procuraram fazer a mesma coisa que fez Jerônimo: corrigir as anteriores versões latinas segundo as versões gregas, agora com documentação que Jerônimo não conheceu. Os evangelhos, traduzidos pelo próprio Jerônimo, foram tratados com muito cuidado, com a ajuda da crítica textual de Kurt Aland..$^{22}$ Para o livro dos Atos, traduzido "duriore stilo", por um autor desconhecido, foi preciso um tratamento mais incisivo (NVg, 1998, p. 22). Quanto às Cartas, os revisores valeram-se de sua especialização na matéria para lhes imprimir um tratamento semelhante ao dedicado aos evangelhos. No Apocalipse, que na $\mathrm{Vg}$ apresenta um texto em latim vivo, os abundantes semitismos e solecismos foram tolerados enquanto compreensíveis, mas as anomalias gramaticais, na medida do possível, emendadas.

Assim, o texto latino ficou mais acurado e "científico", apto para o estudo crítico, sobretudo no NT. Como ilustração, escolhemos entre as centenas de correções, mormente relacionadas com o estilo e a gramática, ${ }^{23}$ alguns exemplos que se referem mais ao conteúdo:

Mt 1,25: a NVg lê, com os melhores e mais antigos textos gregos e muitas traduções antigas, que Maria deu à luz "[um] filho", não "seu filho primogênito" como escrevem o textus receptus e a Vg (a CNBB interpretou "o filho", o que gramaticalmente se justifica, porque o grego nem sempre explicita o pronome definido).

Mt 5,4-5: a NVg coloca "os que choram" $(5,4)$ antes dos "mansos' (5,5), contrariamente à ordem da $\mathrm{Vg}$ e do textus receptus (Tregelles).

Mt 6,6 lê "ora a teu Pai que está em segredo" (cf. todos os mss. gregos) em vez de "ora a teu Pai em segredo" (Vg).

Mt 7,21 elimina da Vg as palavras finais "esse entrará no reino dos Céus", ausentes de todos os mss. gregos.

Mt 7,28 elimina "e os fariseus", acréscimo da Vg ausente de todos os mss. gregos.

Mt 8,28 prefere a lição "gadarenos" (quase geral nos mss. gregos) a "gerasenos" (Vg e mss. latinos), harmonização com Mc 5,1//Lc 8,26.

Mt 8,30: os porcos estão "longe" (cf. todos os mss. gregos), enquanto em Vg e outras versões latinas estão "não longe" (as traduções modernas titubeiam!).

Mt 17,2: as vestes de Jesus são brancas "como a luz" (todos os mss. gregos menos D) e não "como a neve" ( $\mathrm{Vg}, \mathrm{D}$ e algumas versões).

Mt 17,21 é eliminado (presente em $V g$ por assimilação a Mc 9,29). Semelhantes omissões de acréscimos harmonizantes em Mt 18,11; 20,16 etc. Em Mt 24,13 é eliminado o longo acréscimo da edição sixto-clementina.

\footnotetext{
${ }^{22}$ ALAND, Kurt. Synopsis quattuor evangeliorum: locis parallelis evangeliorum apocryphorum et patrum adhibitis edidit. Stuttgart: Württembergische Bibelanstalt, 1963.

${ }^{23}$ P.ex. a omissão de "quod" ou "quia" diante de oração direta etc.
} 
Mt 25,1: corrige-se "(ao encontro) do noivo e da noiva" para "do noivo" só, de acordo com a metáfora escondida do texto (o esposo messiânico).

Mt 27,8: é eliminado o nome aramaico Hacéldama (importado na Vg a partir de At 1,19).

Mc 1,10: o Espírito desce sobre Jesus, mas não "permanece", como escreve a Vg (sob influência de Jo 1,32.33).

Mc 9,30: a tradução errônea "preteriram a Galileia" (Vg) é substituído por "andaram através da Galileia".

Mc 9,44.46 foram eliminados (na Vg, são repetições de 43b combinadas com Is 66,24).

Mc 11,1: foi acrescentada "Betfagé", omitida na $\mathrm{Vg}$.

Mc 16,9-20 (o "final longo") é mantido, mas com uma nota de rodapé observando que falta em alguns mss.

Lc 1,28: omite-se da Vg "bendita (és) tu entre as mulheres"

Lc 2,17: muda-se Vg cognoverunt ("conheceram" ou "reconheceram") para notum fecerunt ("deram a conhecer", "contaram").

Lc 4,44: é restituído a lição original "(nas sinagogas) da Judeia” onde a Vg lia "da Galileia" (indevidamente, pois a administração romana incluía a Galileia na Judeia).

Lc 5,34: o semitismo "os filhos das núpcias" é substituído por "os convivas das núpcias".

Lc 7,47: substitui o futuro "(seus muitos pecados) serão perdoados" (Vg, sem apoio no grego) pelo perfeito lido nos textos gregos: "são perdoados". Analogamente no v. 48.

Lc 8,26: a "região dos gerasenos" (Mc 5,1) é substituída pela "região dos gergeseus".

Lc 8,45c: é retirado o acréscimo "e tu dizes: quem me tocou?"

Lc 9,31: onde a Vg lê excessus, a NVg usa, com o grego, o termo exodus (teologicamente significativo).

Lc 9,35: Jesus é chamado filius meus electus e não dilectus (como em Mc e Mt).

Lc 9,56: retira-se "o Filho do homem não veio perder almas mas salvar" (acréscimo da Vg sixto-clementina cf. Lc 19,10 e Jo 3,17).

Lc 11,11a: omite-se a palavra sobre o pão, julgada harmonização com Mt 7,10. Lc 11,13 escreve "espírito santo" (cf. todos os mss. gregos) em vez de "espírito bom".

Lc 16,20: Lázaro não é chamado "mendigo", mas simplesmente "pobre".

Lc 17,36: excluído como harmonização com Mt 24,40.

Lc 20,23b: excluído como harmonização com Mt/Mc.

Lc 22,43-44 (o anjo consolador e Jesus suando sangue): embora faltando nos melhores mss. e, em outros, deslocado, o texto é mantido por causa de sua ampla divulgação.

Lc 22,68: são excluídas as palavras finais presentes na Vg, "nem me soltais".

Lc 23,15: é excluída a frase "eu o reenviei a vós" (acr. dos mss. gregos tardios).

Lc 23,17: excluído como harmonização com Mt 17,15.

Lc 23,38: é excluída a menção às três línguas no título da cruz (cf. Jo 19,20). 
Lc 24,36: é excluído "sou eu, não tenhais medo", fracamente atestado no grego. Jo 1,9: "vindo ao mundo" é atribuído à "luz" e não ao "homem".

Jo 1,19: "unigênito Deus", não "Filho unigênito" (Vg e outras versões).

Jo 2,15: suprime o quasi ("como que") diante de flagellum ("açoite").

Jo 3,5: "nascido (da água e do espírito") em vez de "renascido...".

Jo 5,2: Bethsatha em vez de Bethsaida.

Jo 5,3b-4: excluído como glosa (falta nos mss. mais antigos e mesmo em parte dos mss. da $\mathrm{Vg}$ ).

Jo 5,41: gloriam em vez de claritatem.

Jo 6,69: Sanctus Dei em vez de Christus Filius Dei.

Jo 8,1-11, embora reconhecido em nota como acréscimo, é mantido no texto como canônico (situação diferente de 5,3b-4).

Jo 9,11: Siloam em vez de natatoria Siloam

Jo 20,17: noli me tenere em vez de noli me tangere.

At 15,34: omitido (acréscimo da Vg sixto-clementina).

At 16,37: restauração do termo essencial occulte, ausente na $\mathrm{Vg}$.

At 24,6c-7: omitido (acréscimo da Vg sixto-clementina).

At 28,29: omitido (acréscimo da Vg sixto-clementina).

Rm 5,12: em vez de "(Adão) no qual" (in quo) "todos pecaram", lê "porque" (eo quod).

Rm 8,3: em vez de de peccato (originado do pecado), lê (com o grego) pro peccato (por causa do pecado).

1Cor 7,36: em vez de "que se case" (aquele homem), lê "que se casem" (a virgem e o pretendente).

1Cor 8,12: "(pecais) contra Cristo (in Christum) em vez de "em Cristo" (in Christo).

1Cor 13,3: "(se entregar meu corpo) para me gloriar" em vez de "para queimar". ${ }^{24}$

Gl 3,24: "(A Lei foi como nosso educador) conduzindo a Cristo" (in Christum) em vez de "em Cristo" (in Christo).

Ef 1,9: mysterium em vez de sacramentum.

Ef 3,11: propositum saeculorum em vez de praefinitionem saeculorum.

Ef 5,32: mysterium em vez de sacramentum.

Fl 2,13: traduz gr. eudokia por beneplacitum em vez de bona voluntas (Vg) ${ }^{25}$

Cl 1,27: mysterium em vez de sacramentum.

$\mathrm{Hb}$ 1,13: substitui o incompreensível Deus intemptator malorum est por Deus enim non tentatur malis.

2Pd 1,6: continentia em vez de abstinentia.

1Jo 5,7: omite o "comma ioanneum": Pater, Verbum et Spiritus Sanctus. ${ }^{26}$

\footnotetext{
${ }^{24}$ Paulo parece aludir à prática de alguém se entregar para redimir outro da escravidão; porém, se for por vanglória, sem caridade, para nada serve.

${ }^{25}$ Infelizmente não fez a mesma coisa em Lc 2,14!

${ }^{26}$ Omitido já na edição de estudo da Vg (BIBLIA Sacra, 1969), o "comma" foi objeto de declarações do Santo Ofício em 1897 e 1927 (DH, n. 3681-3682).
} 
Como era de se esperar, as modificações suscitaram críticas tanto da parte de conservadores católicos quanto da parte de historiadores, que acham que a NVg deformou a obra de Jerônimo - objeção que já apartamos explicando que a $\mathrm{NVg}$ não é uma restauração do texto histórico da $\mathrm{Vg}$, mas uma tradução nova.

Levando em conta a intenção do Concílio, uma crítica aceitável seria dizer que o projeto foi executado com demasiada pressa (entre 1966 e 1978), enquanto outros projetos similares levam muito mais tempo. Contudo, tal rapidez foi possível porque a elaboração se baseou nas pesquisas constantemente atualizadas dos grandes centros de crítica textual, independentemente de serem católicos ou não. Deste modo, a Nova Vulgata foi, de fato, um bom exemplo de colaboração acadêmica e ecumênica, assim como aconselha a Dei Verbum (DV, n. 22).

Portanto, a Igreja não adotou uma versão corrigida da antiga Vulgata, mas substituiu a antiga Vulgata pela Nova Vulgata como nova tradução oficial. Desde 1979 não se pode mais dizer, como infelizmente se continua repetindo, que a Vulgata é a tradução bíblica oficial da Igreja Católica. Porém, como sugere o Concílio Vaticano II, a Vulgata foi amplamente aproveitada e continua sendo uma testemunha de inestimável valor para a conservação e compreensão da tradição bíblica, que interessa não só à Igreja Católica, mas à cultura universal.

\section{Da Nova Vulgata à nova tradução "oficial" da CNBB}

A tradução oficial da CNBB procurou proceder no mesmo espírito da $\mathrm{NVg}$ : melhorar o texto com base nos documentos originais, respeitando a interpretação eclesial essencial. Assim como a NVg, a tradução da CNBB usou como base científica as atuais edições críticas dos originais hebraicos (e aramaicos) para os protocanônicos do AT, e dos originais gregos para os deuterocanônicos do AT e para o NT, sempre ladeados com a NVg. Propriamente, portanto, é uma tradução, não da $\mathrm{NVg}$, mas dos originais segundo o exemplo da NVg.

Em breves linhas, é possível perceber como essa opção se justifica pelo histórico dos trabalhos e deliberações das instâncias competentes da CNBB.

Segundo consta nos arquivos da CNBB, durante a $25^{\text {a }}$ reunião da CEP (Comissão Episcopal Pastoral), datada de 26 a 28/11/1989, discutiu-se a questão das diversas traduções da Bíblia existentes no Brasil (CNBB, 1989, p. 1762). Ao mesmo tempo em que se reconheceu que a presença de diversas traduções revelava uma ampla difusão da Bíblia entre os católicos brasileiros, concluiu-se, também, que a diversidade de traduções trazia 
consigo algumas dificuldades como, por exemplo, ao uso comunitário da Bíblia em encontros espirituais e pastorais e à oportuna memorização dos textos bíblicos.

Em comunicado de Dom Vital J. G. Wilderink e de Dom Clemente J. C. Isnard, respectivamente presidentes das Linhas 3 e 4 da CNBB, considerou-se a necessidade de uma tradução da "Bíblia Oficial Popular" (CNBB, 1989, p. 1762), a partir dos textos da Neovulgata, reconhecidos como os que "mais facilmente podem ser memorizados pelo povo" (CNBB, 1989, p. 1762). Os dois bispos concluem que "as traduções dos textos originais poderiam servir para os seminários e especialistas" (CNBB, 1989, p. 1763).

Em outra reunião da CEP, Dom Clemente Isnard apresentou um retrospecto histórico sobre a tradução única da Bíblia para uso litúrgico (CNBB, 1990, p. 1078-1080). Ele recordava que:

Na 14aㅡ Assembleia Geral da CNBB (AG), ocorrida em 1974, pela primeira vez os bispos manifestaram-se a respeito dos textos bíblicos usados durante as celebrações litúrgicas. Naquela AG decidiu-se que: a CNBB daria início a uma tradução oficial dos textos bíblicos para uso na liturgia; a elaboração de tal tradução seria confiada à Liga de Estudos Bíblicos (LEB) e aprovada pela comissão competente da CNBB; a tarefa de revisão e adaptação permanente da tradução seria confiada à LEB, de acordo com a evolução da linguagem, a cada dez anos.

Na 15ª AG (1977), aprovou-se que a tradução oficial dos textos bíblicos para uso na liturgia seria escolhida pela Comissão Nacional de Liturgia e sua aprovação final seria dada pela CEEATTL (Comissão Episcopal para Exame e Aprovação de Traduções de Textos Litúrgicos).

Na 19a AG (1981), surgiu um plano de trabalho para a tradução definitiva, conforme os lecionários, a acontecer de 1981 a 1987. Em 1987, ocorreu uma revisão e decidiu-se por fazer uma tradução de todos os textos, antes da publicação dos diversos lecionários. Nesta ocasião, por exigência da Sé Apostólica, confirmou-se que o texto de referência deveria ser a Neovulgata. Na mesma ocasião, pensou-se numa possível Bíblia catequético-litúrgica, mas a ideia foi abandonada por premência de tempo. Pensou-se, ainda, em adotar a Bíblia Pastoral, ${ }_{1}^{27}$ mas por motivos de direitos autorais e demora na conclusão da mencionada edição pastoral, abandonou-se essa ideia. Decidiu-se, então, que se iniciaria uma tradução própria da CNBB dos textos usados na liturgia. Suspendeu-se, assim, a ideia da Bíblia litúrgica ou catequético-litúrgica, a ser retomada no futuro.

${ }^{27}$ A edição completa foi publicada pela Edições Paulinas em 1989. 
Na mesma ocasião, foram levantadas, sem resposta descrita em Ata, questões relevantes tais como: A CNBB traduziria toda a Bíblia ou somente os textos que ocorrem na liturgia? A tradução partiria dos textos originais ou da Neovulgata?

Na AG de 1991 (CNBB, 1991, p. 550-557), a convite de Dom Clemente Isnard, o jesuíta Johan Konings apresentou as linhas gerais do problema da tradução única da Bíblia, destacando os elementos mais importantes para uma decisão da Assembleia. Entre os elementos centrais de sua exposição sobre a tradução única da Bíblia, ele destacou como vantagens: a memorização dos textos, a concentração dos esforços dos biblistas em torno de uma tradução de qualidade superior e, devido a seu caráter oficial, a tradução suscitaria a produção de intervenções de estudiosos.

A tradução serviria, assim, "de referência oficial para o uso pastoral, especialmente litúrgico-catequético" (CNBB, 1991, p. 554), ao mesmo tempo, com qualidade científica e linguística de um lado, e o caráter popular adequado às diversas regiões e situações do Brasil, de outro.

Entre as propostas com relação à identidade da tradução, foi proposto que: ela se baseasse no texto original hebraico e grego e na Neovulgata, normativa para as traduções litúrgicas; tivesse um número reduzido de notas e se caracterizasse por uma linguagem "proclamável" e simples, mas não trivial.

Após a fala de Johan Konings, a AG votou positivamente com 90,4\% dos votantes que a Neovulgata se tornasse o texto-base para a edição da bíblia litúrgico-catequética, Bíblia oficial da CNBB.

No dia 31 de outubro de 1991, houve a primeira reunião da Comissão do Projeto bíblia litúrgico-catequética da CNBB sob a presidência de Dom Albano Cavallin ${ }^{28}$. Naquela ocasião, decidiu-se que a tradução seria feita a partir dos originais em conformidade com a Neovulgata. Dom Clóvis Frainer, eleito diretor responsável das reuniões com os biblistas que comporiam o grupo de tradutores, ponderou que até 30/06/1995 a tradução estivesse pronta.

No dia 12 de março de 1992, em reunião da comissão do projeto da bíblia litúrgico-catequética, presidida por Dom Albano Cavallin, ficou decidido, entre outras prioridades, que a base da tradução seria a Neovulgata. ${ }^{29}$

\footnotetext{
${ }^{28}$ Participaram da reunião: Dom Clóvis Frainer, Dom Sebastião Roque Rabelo Mendes, Pe. Johan Konings, Pe. Walmor Oliveira de Azevedo e Inês Broshuis. Na mesma reunião, decidiu-se convidar para a supervisão exegético-literária o Pe. José Luiz do Prado. Cf. CNBB, 1991, p. 1993.

${ }^{29}$ Participaram da reunião: Dom Clóvis Frainer, Dom Sebastião Roque Rabelo Mendes, Pe. Johan Konings, Pe. Walmor Oliveira de Azevedo, Pe. José Luiz G. do Prado, Pe. Ney Brasil, Frei Ludovico Garmus e Inês Broshuis. Cf. CNBB, 1992, p. 409.
} 
Em carta do dia 8 de agosto de 1994, o coordenador da tradução, Johan Konings escreve a Dom Albano Cavallin, propondo a publicação do NT a ser planejada para o ano seguinte, 1995.

Na 34를 AG ocorrida em 1996, Dom Vital Wilderink dirigiu-se aos bispos discursando sobre "a Bíblia Oficial da Igreja no Brasil" (CNBB, 1996, p. 709-712), quando, após ter traçado um breve histórico, mencionou o principal desafio da tradução: a dificuldade de manter inalterados os textos dos lecionários recém-publicados. Ele recordou, ainda, que a tradução dos textos bíblicos para uso litúrgico requereria a aprovação da Santa Sé, o que atrasaria a publicação da esperada edição da Bíblia. Propôs, então, uma edição que fosse "uma Bíblia catequética ou comunitária, aprovada, como texto oficial, pelo Presidente da CNBB" (CNBB, 1996, p. 711).

Estabeleceu duas perguntas para votação da AG: publicar-se-ia a Bíblia oficial da CNBB, mantendo inalteradas as perícopes litúrgicas já aprovadas pela Santa Sé ou publicar-se-ia o texto traduzido, levando em conta as diferenças relacionadas às perícopes litúrgicas já publicadas? No caso da segunda proposta, esta poderia tornar-se, no futuro, uma referência para a edição dos livros litúrgicos a serem aprovados pela Santa Sé. A quase totalidade dos Bispos preferiu a segunda hipótese: a publicação de uma Bíblia de texto contínuo, a tornar-se a tradução oficial da CNBB (CNBB, 1996, p. 712).

Em 2000, em comunicado de Johan Konings (CNBB, 2000, p. 1421-1426), passa a ser usada a terminologia "Bíblia de referência", para indicar que a Bíblia deveria ser citada em textos oficiais da Igreja do Brasil e usada na atualização dos livros litúrgicos. Ele expõe que, na tradução, foram privilegiadas a clareza, a proclamabilidade, a proximidade das perícopes lidas na liturgia e a fidelidade aos textos originais segundo a Neovulgata. Ainda, no mesmo texto, Konings justifica que a Neovulgata não é considerada como o texto-base, mas como a orientadora, pois textos-base são aqueles nos idiomas originais (CNBB, 2000, p. 1422). A comissão tradutora quis seguir o exemplo da Igreja Católica Italiana, em sua Bíblia oficial, que adotou a mesma posição. Fica decidido que "nos raros casos em que os tradutores julgam dever apresentar uma tradução que, quanto ao conteúdo, se afasta da Nova Vulgata, esta é mencionada em nota, para que o leitor possa sempre conhecer a interpretação da Nova Vulgata" (CNBB, 2000, p. 1422).

Em 20 de julho de 2001, houve o ato de lançamento da Bíblia durante o 14ํㅡㄹ Congresso Eucarístico, em Campinas (CNBB, 2001, p. 838-839; p. 12301231). Johan Konings, em seu discurso, recordava que a CNBB "oferece uma versão 'adequada e correta' dos Livros Sagrados a partir dos textos originais (em hebraico, aramaico e grego). Todavia, visto a proximidade 
à liturgia e o desejo dos últimos Papas, levou-se cuidadosamente em consideração o modelo da Nova Vulgata" (CNBB, 2001, p. 478-481; p. 838).

Em reunião ocorrida em Brasília, 26 de agosto de 2004,,$^{30}$ ficou decidido que enquanto os aspectos administrativos e a coordenação dos trabalhos ficariam a cargo do secretário geral, à comissão de Doutrina caberia averiguar a fidelidade da tradução ao texto sagrado, à comissão de Liturgia o uso litúrgico da Bíblia e à comissão Bíblico-catequética a aplicação pedagógica da Bíblia.

Em 2007, o presidente da Comissão de Doutrina da CNBB, naquela ocasião, Dom Walmor Oliveira de Azevedo, solicitou que se iniciasse o processo de revisão da Bíblia da $\mathrm{CNBB}$, com o propósito de que pudesse se tornar o texto oficial da Conferência Episcopal, inclusive para o uso litúrgico. No início, pensou-se que o trabalho deveria ser realizado com a participação de três comissões episcopais pastorais da CNBB: Doutrina, Liturgia e Bíblico Catequética. Com isso, pensava-se que com este trabalho poder-se-iam alcançar as metas previstas de uma Bíblia Oficial para a Catequese e para a Liturgia, com as tramitações e exigências próprias para se alcançar este status. No caso da liturgia, seria ainda necessário o reconhecimento próprio da Congregação para a Liturgia e a Disciplina dos Sacramentos.

Em comunicado (março de 2008) Konings informa: "Nos quinze anos que nos separam dos primeiros passos apareceram fatores novos que devem ser levados em consideração. Tem-se um olhar mais crítico em relação ao caráter 'popular' da tradução de referência. Para ter um caráter confiável, a tradução de referência deve ser mais aderente aos textos originais, em harmonia com a Nova Vulgata, que é uma tentativa de aproximar a tradicional Vulgata dos textos originais". Diante da indicação do presidente da Comissão de Doutrina, a citação de Konings indica a necessidade de uma revisão acurada em harmonia com a Neovulgata.

Posteriormente, diante da ausência de competências adequadas e de especialistas que pudessem incorporar o trabalho com unidade de princípios, decidiu-se concentrar o trabalho de revisão somente sob a presidência da Comissão de Doutrina em estreita relação com o secretário da CNBB, para que o trabalho pudesse seguir a contento diante das novas exigências a serem cumpridas. Aquela que tinha sido uma característica da primeira fase, a participação de diversos especialistas, como ocorre com muitas outras opções de tradução como a da Bíblia de Jerusalém, por exemplo,

\footnotetext{
${ }^{30}$ Participaram da reunião: Dom Odilo P. Scherer, secretário geral, os presidentes das comissões pastorais para a Doutrina da Fé, Bíblico-catequética e Liturgia, respectivamente Dom Walmor O. de Azevedo, Dom Eugène L. A. Rixen e Dom Manoel João Francisco, o coordenador da tradução Pe. Johan Konings, o assessor jurídico da CNBB, Dr. Luiz Carlos M. A. Júnior e a funcionária Irene Rodrigues do setor de publicações e direitos autorais. Cf. CNBB, 2004, p. 1826-1827.
} 
revelou-se inviável no caso da Bíblia da CNBB e a equipe reduziu-se para um grupo permanente: Pe. Johan Konings, Pe. Ney Brasil e Pe. Luís Henrique Eloy e Silva, nomeado coordenador da tradução. Três colaboradores não permanentes fizeram parte: Pe. Cassio Murilo Dias da Silva (atualmente professor da PUC de Porto Alegre que colaborou nos livros de Gn, Ex, Profetas anteriores), Dom Paulo Jackson Nóbrega de Souza, à época professor da PUC Minas e da Faculdade Jesuíta de Belo Horizonte (que colaborou em parte na tradução dos escritos Paulinos) e Profa. Maria de Lourdes Corrêa Lima, da PUC Rio (que traduziu os Profetas Menores). Optou-se por uma equipe menor a fim de se favorecer uma maior coesão na dinâmica do trabalho e, ao mesmo tempo, alcançar maior acribia nos critérios metodológicos adotados.

O critério preponderante e guia dos trabalhos passa a ser o da coerência semântica, ao interno dos livros e ao interno dos autores. No primeiro caso, quando se analisa o mundo interno de cada livro, busca-se a fidelidade ao estilo do autor, não somente no que tange à aproximação lexical, mas também sintática. Por isso, dentro do possível, sem cair no literalismo, os termos que se repetem ao interno do livro são traduzidos da mesma forma, bem como as células sintáticas preferidas pelo autor. Além disso, atenção passa a ser dada à teologia de cada autor, para que os termos traduzidos resplandeçam mais adequadamente a mensagem veiculada pelo texto. No segundo caso, para além do mundo interno de cada texto, passam a ser analisados livros atribuídos ao mesmo autor como, por exemplo, escritos lucanos, paulinos e joaninos, nos quais foi criteriosamente buscada a coerência morfossintática e semântica.

Relevante menção deve ser dada ao trabalho realizado em relação aos evangelhos sinóticos. Nesse caso, as perícopes sinóticas, plenas ou parciais, passaram por uma adequação literal e semântica a fim de ajudar o leitor, não somente na memorização desses textos, mas também no vínculo de suas riquezas e particularidades.

\section{Conclusão}

Ao verificarmos as raízes da tradução da Bíblia Oficial da CNBB, demo-nos conta de que ela se insere no filão da tradição católica ocidental, para a qual sempre houve uma Bíblia de referência seja para a lex credendi, seja para a lex orandi, antes a Vulgata e, posteriormente, a Neovulgata. A Neovulgata revelou-se uma obra nova, de caráter eclesiástico-institucional e pastoral, e não somente uma edição crítica da Vulgata de Jerônimo.

A Bíblia Sagrada, tradução oficial da CNBB, encontra-se no mesmo filão da Neovulgata. Como ela, "leva em conta as novas descobertas documentais 
e a crescente valorização das antigas traduções gregas, siríacas, egípcias e latinas, às vezes mais antigas ou de maior importância para a Igreja primeva que os textos comumente considerados como os mais originais" (Bíblia da CNBB, 2018, p. 7), como ela busca servir de interlocução com a tradição litúrgico-catequética e espiritual da Igreja, a serviço da vida da comunidade eclesial e da proclamação da Palavra e, por isso mesmo, insere-se também na compreensão de uma tradução acadêmica e pastoral. Com efeito, o cuidado científico que percorreu o processo da tradução, sua atenção em função da adequação ao uso litúrgico e sua preocupação com a exata compreensão dos termos bíblicos situa a tradução da Bíblia da CNBB no rol de uma tradução com preocupações pastorais (Bíblia da CNBB, 2018, p. 7). Um claro exemplo dessas preocupações é a tradução de At 1,17 em que a frase "derramarei o meu Espírito sobre toda carne", da versão anterior da Bíblia da CNBB (Bíblia da CNBB, 2007), baseada na equivalência formal do grego sarx, foi traduzida por "derramarei o meu Espírito sobre todos", optando pela equivalência funcional do mesmo termo, que nesse caso, pareceu mais compreensível ao leitor contemporâneo.

\section{Siglas}

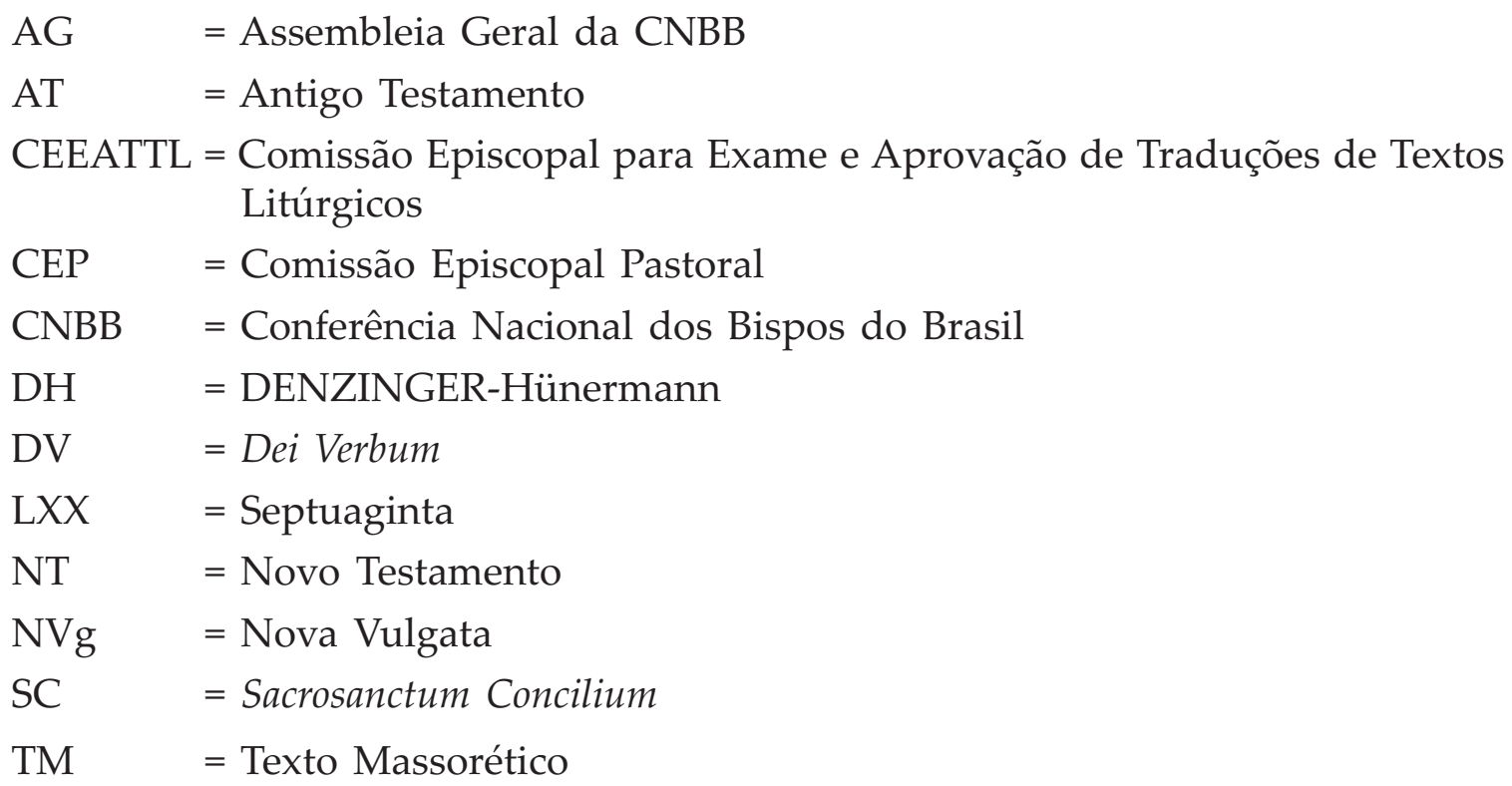

\section{Referências}

ALAND, K. et alii. The Greek New Testament. 3.ed.corr. USA: United Bible Societies, 1975.

ALAND, K. Synopsis quattuor evangeliorum: locis parallelis evangeliorum apocryphorum et patrum adhibitis edidit. Stuttgart: Württembergische Bibelanstalt, 1963.

BIBLIA Sacra Vulgata. 3.ed. Stuttgart: Württembergische Bibelanstalt, 1969. 2 v. 
CONCÍLIO VATICANO II. Constituição dogmática Dei Verbum sobre a revelação divina. Acessível em: <https://www.vatican.va/archive/hist_councils/ii_vatican_council/documents/vat-ii_const_19651118_dei-verbum_po.html>. Acesso em: 26 out. 2019 .

CONFERÊNCIA NACIONAL DOS BISPOS DO BRASIL. Bíblia Sagrada: tradução oficial da CNBB. Brasília: CNBB, 2018.

CONFERÊNCIA NACIONAL DOS BISPOS DO BRASIL. Comunicado Mensal, novembro de 1989.

CONFERENCIA NACIONAL DOS BISPOS DO BRASIL. Comunicado Mensal, agosto de 1990.

CONFERÊNCIA NACIONAL DOS BISPOS DO BRASIL Comunicado Mensal, abril de 1991.

CONFERENCIA NACIONAL DOS BISPOS DO BRASIL. Comunicado Mensal, abril de 1992.

CONFERENCIA NACIONAL DOS BISPOS DO BRASI. Comunicado Mensal, abril de 1996.

CONFERÊNCIA NACIONAL DOS BISPOS DO BRASIL. Comunicado Mensal, julho/ agosto de 2000.

CONFERÊNCIA NACIONAL DOS BISPOS DO BRASIL. Comunicado Mensal, abril/ maio de 2001.

CONFERÊNCIA NACIONAL DOS BISPOS DO BRASIL. Comunicado Mensal, julho/ agosto de 2001.

CONFERENCIA NACIONAL DOS BISPOS DO BRASIL. Comunicado Mensal, outubro de 2004.

DENZINGER, H. Compêndio dos símbolos, definições e declarações de fé e moral. 2.ed. atualizado por P. Hünermann. São Paulo: Loyola, 2013.

ELLIGER, K.; RUDOLPH, W. (Eds.). Biblia hebraica stuttgartensia. Stuttgart: Deutsche Bibelgesellschaft, 1967/77.

JOÃO PAULO II, Papa. Constituição apostólica Scripturarum Thesaurus que declara como típica e promulga a edição Neovulgata da Bíblia. Disponível em: <http:// www.vatican.va/content/john-paul-ii/pt/apost_constitutions/documents/hf_jp-ii_apc_19790425_scripturarum-thesaurus.html>. Acesso em: 26 out. 2019.

LA BIBLE. Traduction oecuménique. Paris: Cerf, 1975-1976. 2 v.

NESTLE-ALAND. Novum Testamentum graece. 26.ed. Stuttgart: Deutsche Bibelgesellschaft, 1979.

NOVA VULGATA Bibliorum Sacrorum Editio. Editio iuxta editionem typicam alteram. Citta del Vaticano: Libreria Ed. Vaticana, 1998.

PAULO VI. Papa. [Alocução de 23 de dezembro de 1966] Acta Apostolicae Sedis., LIX, 1967, p. 48-59. Disponível em: <http://www.vatican.va/archive/aas/documents/ AAS-59-1967-ocr.pdf.> Acesso em: 29 abril 2020. 
PIO XII, Papa. Divino Afflante Spiritu. Disponível em: <http://w2.vatican.va/content/ pius-xii/pt/encyclicals/documents/hf_p-xii_enc_30091943_divino-afflante-spiritu. html>. Acesso em: 29 out. 2019.

RAHLFS, A. (Ed.). Septuaginta: id est Vetus Testamentum graece iuxta LXX interpretes. 9.ed. Stuttgart: Deutsche Bibelstiftung, 1935. 2 v.

REICHMANN, V. Bibelübersetzungen 3.3 Zur Geschichte der Vulgata. In: Theologische Realenzyklopädie. Berlin: De Gruyter, 1980. v. 6, p. 178-182.

SCHÄFER, K. T. Lateinische Bibelübersetzungen. In: Lexikon für theologie und Kirche. 2.ed. Freiburg: Herder, 1958. v. 2. coluna 380-384.

Artigo submetido em 04.02.2020 e aprovado em 06.04.2020.

Johan Konings SJ é Doutor em Teologia e Licenciado em Filologia Bíblica pela Katholieke Unversiteit Leuven (Bélgica). Professor do Departamento de Teologia da Faculdade Jesuíta de Filosofia e Teologia (FAJE). Contribuição no artigo: estruturação, introdução e itens 1 e 2. Orcid.org/0000-0001-7200-0753. E-mail: konings@faculdadejesuita.edu.br

Endereço: Av. Dr. Cristiano Guimarães, 2127

Planalto

31720-300 Belo Horizonte - MG

Luís Henrique Eloy e Silva é Doutor em Ciência Bíblica pelo Pontifício Instituto Bíblico de Roma (2006); pós-doutor em Hermenêutica Bíblica pela Faculdade de Teologia da Universidade Ludwig Maximilian de Munique (2018). Professor de exegese do NT na Pontifícia Universidade Católica de Minas Gerais (PUC-MG) e na Faculdade Jesuíta de Filosofia e Teologia (FAJE). Membro da Pontifícia Comissão Bíblica. Contribuição no artigo: estruturação, item 3 e conclusão. Orcid.org/0000-0002-0373-8591. E-mail: padreluishenrique@hotmail.com

Endereço: Rua José Batista Ribeiro, 155

São Bento

30350-740 Belo Horizonte - MG 